\title{
Rapid Resolution Liquid Chromatography Method for Determination of Malathion in Pesticide Formulation
}

\author{
L. Velkoska-Markovska* and B. Petanovska-Ilievska \\ Ss. Cyril and Methodius University, Faculty of Agricultural Sciences and Food - Skopje, \\ 16-ta Makedonska brigada No. 3, 1000 Skopje, Republic of North Macedonia
}

Received: 18 Sep 2019; accepted: 12 Oct 2019

\begin{abstract}
This paper presents a new, simple, precise, and accurate rapid resolution liquid chromatography (RRLC) method for determination of an active ingredient malathion in the pesticide formulation. The analysis was performed on a Poroshell EC 120-C18 $(50 \mathrm{~mm} \times 3 \mathrm{~mm}, 2.7 \mu \mathrm{m})$ analytical column using isocratic elution with a mobile phase consisted of acetonitrile-water $(50: 50, \mathrm{v} / \mathrm{v})$, a flow rate of $1 \mathrm{~mL} / \mathrm{min}$, a constant column temperature at $25^{\circ} \mathrm{C}$, and ultravioletdiode array detection (UV-DAD) at $220 \mathrm{~nm}$. The specificity, selectivity, linearity, precision, and accuracy were tested for the method validation according to the Collaborative International Pesticides Analytical Council (CIPAC) and Directorate General Health and Consumer Protection (SANCO) guidelines and all tested parameters were found within acceptance criteria. The obtained results indicated that the proposed method can be used for routine analysis of the active ingredient malathion in the pesticide formulation "Etiol tecni" following the CIPAC and SANCO rules. The run time of analysis under the stipulated chromatographic conditions was about 2.5 min, meaning that the proposed method requires a small volume $(<1.5 \mathrm{~mL})$ of the organic solvent (acetonitrile) making it cost-effective.
\end{abstract}

Keywords: RRLC method, UV-DAD, malathion, pesticide formulation

\section{Introduction}

Since ancient times, the harmful effects of insects on food, domestic animals, and humans have been observed, and insecticides have been used to destroy them. Recent research has focused on the synthesis of new organophosphorus compounds that are less toxic to humans and more effective at destroying insects and other harmful biological agents. Organophosphorus insecticides are widely used because of their relatively rapid decomposition and low accumulation in living organisms. One of the most used organophosphorus insecticides in our country and in the world is malathion, which has been approved for use according to the European Commission Regulation (EC) No 1107/2009 [1] and EPA [2], etc. Malathion (Figure 1a) is a generally accepted name according to the International Organization for Standardization (ISO), while according to IUPAC (International Union of Pure and Applied Chemistry) the name of this active component is diethyl(dimethoxythiophosphorylthio)succinate; S-1,2-bis(ethoxycarbonyl)ethyl-O,O-dimethyl phosphorodithioate [3].

Malathion is a non-systematic insecticide and acaricide of low mammalian toxicity, with contact, stomach, and respiratory action. In addition, it is a cholinesterase inhibitor [3]. Malathion is present as an active substance in many pesticide products, including "Etiol tecni", which is in the form of emulsifiable concentrate (EC).

New pesticide formulations are constantly being developed, which represent ever-better solutions to suppress harmful biological agents, thereby increasing the need for constant quality control of the pesticides placed on the market. This is especially important because the quality of plant protection products affects the crop safety, as well as the environment and the human health. The improvement of existing and, in particular,

*Author for correspondence: levemar@gmail.com; lencevm@fznh.ukim.edu.mk. the development of new analytical methods for the determination of active substances in plant protection products are necessary to control the quality of pesticide formulations.

The literature search shows that various analytical methods for determining malathion in different matrices are known. Thus, for example, the determination of malathion and its residues can be performed using gas-liquid chromatography (GLC) [3]. More than 30 years ago, malathion in pesticide formulations was determined by volumetric methods such as argentometric [4], iodometric [5, 6], or complexometric following alkaline hydrolysis [7, 8]. Also used are spectrophotometric methods [9, 10], atomic absorption spectroscopy (AAS) [11], gas chromatography (GC) [12], or by environmental friendly methods such as Fourier transform infrared spectroscopy (FTIR) [13] and Fourier transform Raman spectroscopy (FTRS) [14]. Collaborative International Pesticides Analytical Council (CIPAC) has published reference methods using gas-liquid chromatography [15] and gas chromatography [16] for the determination of active substance malathion in technical material (TC), dustable powders (DP), wettable powders (WP), emulsifiable concentrates (EC), oil miscible liquid $(\mathrm{OL})$ and emulsion, and oil in water (EW).

The literature search shows that only a small number of publications are related to the analysis of active substances in the pesticide formulation and their quality control. However, to date, no analytical method for the determination of malathion in pesticide formulations by liquid chromatography (LC) has been published in the literature. Hence, the aim of this study was to develop a new, simple, fast, and convenient method for the determination of malathion in pesticide formulation in the form of an emulsifiable concentrate using rapid resolution liquid chromatography (RRLC) method with ultraviolet-diode array detection (UV-DAD). The research within this paper represents contribution in the field of new analytical methods for determination of active substances in the plant

This is an open-access article distributed under the terms of the Creative Commons Attribution-NonCommercial 4.0 International License (https://creativecommons.org/licenses/by-nc/4.0/), which permits unrestricted use, distribution, and reproduction in any medium for non-commercial purposes, provided the original author and source are credited, a link to the CC License is provided, and changes - if any - are indicated. 
<smiles>CCOC(=O)CC(SP(=S)(OC)OC)C(=O)OCC</smiles>

(a)

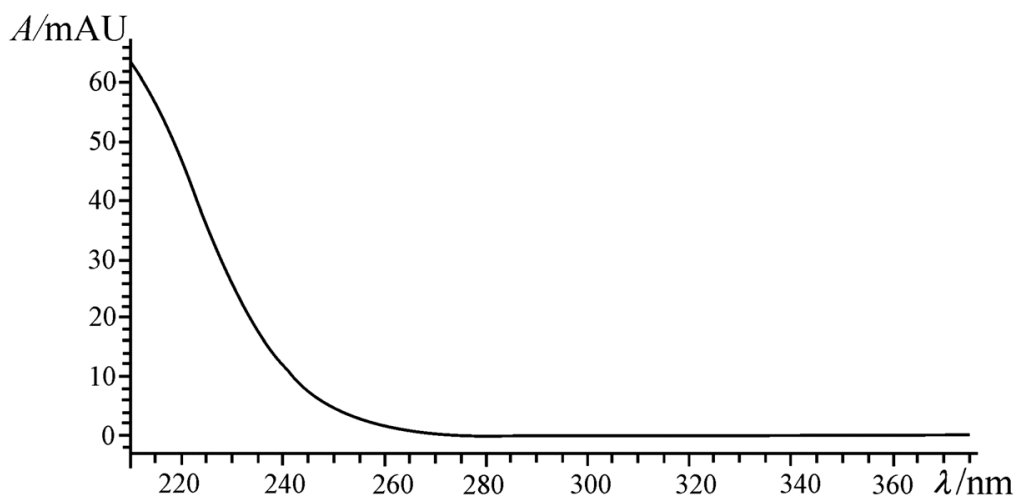

(b)

Figure 1. Chemical structure of malathion (a) and its UV spectrum in acetonitrile-water $(50: 50, v / v)$ (b)

protection products. The development and publication of new analytical methods for analysis of pesticides enable control laboratories to save time and money in developing of their own methods and to carry out more efficient quality control of these products.

\section{Experimental}

Equipment and Materials. The chromatographic analysis was performed on an Agilent 1260 Infinity Rapid Resolution Liquid Chromatography (RRLC) system equipped with the following: a vacuum degasser (G1322A), a binary pump (G1312B), an autosampler (G1329B), a column compartment (G1316A), a UV-vis diode array detector (G1316B), and ChemStation software. The experiments were carried out using a Poroshell EC 120-C18 $(50 \mathrm{~mm} \times 3 \mathrm{~mm}, 2.7 \mu \mathrm{m})$ analytical column produced by Agilent Technologies (USA).

For the better dissolving of the stock solution and sample solution, an ultrasonic bath "Elma" was used.

The Pestanal analytical standard of malathion (97.2\% purity), as well as HPLC-grade acetonitrile and water, were purchased by Sigma-Aldrich (Germany).

The pesticide formulation "Etiol tecni", which was in the form of an emulsifiable concentrate (EC) was produced by "Galenika-fitofarmacija" (Belgrade, Serbia). The declared value for the content of malathion was $600 \mathrm{~g} / \mathrm{L} \pm 25 \mathrm{~g} / \mathrm{L}$, and for density, it was $1.075 \mathrm{~g} / \mathrm{mL}$.

Preparation of Standard Solutions. Stock solution of malathion was prepared by dissolving $0.0330 \mathrm{~g}$ of the pure analytical standard with acetonitrile in a $25-\mathrm{mL}$ volumetric flask. To perform better dissolution of the active component, the prepared stock solution was ultrasonicated for $15 \mathrm{~min}$ in an ultrasonic bath. The stock solution was stored in a refrigerator at $4{ }^{\circ} \mathrm{C}$. Under these conditions, the stability of the active component was greater than 1 month. During the tests, working standard solutions were prepared by diluting the stock solution with a mixture of equivalent volumes of acetonitrile and water in 10-mL flasks.

To test the linearity of the method, a series of 5 working standard solutions with a concentration of 46.75, 93.50, $187.00,280.50$, and $374.00 \mu \mathrm{g} / \mathrm{mL}$ were prepared. Each of these working solutions was injected three times with a volume of $5 \mu \mathrm{L}$.

Preparation of Sample Solution. For the quantitative determination of the active ingredient malathion, $0.0333 \mathrm{~g}$ of the pesticide formulation "Etiol tecni" was weighed in a 10 $\mathrm{mL}$ volumetric flask and dissolved in equal volumes of acetonitrile and water. The solution was degassed for $15 \mathrm{~min}$ in an ultrasonic bath, and then a portion of $0.5 \mathrm{~mL}$ volume was transferred to a $10-\mathrm{mL}$ volumetric flask and supplemented with a mixture of equal volumes of acetonitrile and water. Four injections were performed with a volume of $5 \mu \mathrm{L}$ of this solution. Filtering the sample solution was not required because of its complete solubility in the solvents used.

To determine the recovery of the method in 3 flasks of $10 \mathrm{~mL}, 0.5 \mathrm{~mL}$ of the prepared sample solution was taken. To each solution was added a known quantity of analytical standard of malathion: 23.37, 46.75, and $93.49 \mu \mathrm{g} / \mathrm{mL}$. The flasks were then filled up to the mark with a mixture of acetonitrile and water at a volume ratio of 50:50. Four injections were performed with $5 \mu \mathrm{L}$ of each of these solutions.

\section{Results and Discussion}

Chromatography Study. The choice of wavelength on which the chromatographic analyses was performed was based on the UV spectrum of malathion recorded in a solution of acetonitrile and water $(50: 50, v / v)$. The UV spectrum of malathion is presented in the Figure $1 \mathrm{~b}$. As can be seen from the UV spectrum of malathion, the maximum band cannot be noticed, but it is observed that the absorption increases with decreasing wavelength. Hence, the chromatographic analysis for the determination of malathion in the pesticide formulation was carried out at $220 \mathrm{~nm}$.

Investigations were performed on Poroshell 120 EC-C18 $(50 \mathrm{~mm} \times 3 \mathrm{~mm}, 2.7 \mu \mathrm{m})$ analytical column. Poroshell 120 was selected as the stationary phase, because it provides exceptional efficiency, i.e., increased speed and, at the same time, increased resolution of the chromatographic process within the existing pressure range of current instruments and higher resolution and speed of new LC and LC-MS systems enable work at higher pressures [17]. These columns are mechanically stable and can be used up to a pressure of 600 bar (9000 psi) and a temperature of up to $60{ }^{\circ} \mathrm{C}$. Poroshell 120 EC-C18 is intended for reversed-phase chromatography and can be used for base, neutral, or acid samples at a $\mathrm{pH}$ of 2 to $9[18,19]$.

In order to develop a simple RRLC method for the determination of the active component of malathion in a pesticide formulation, the chromatographic process was run using an isocratic elution, i.e., by the use of constant composition of the mobile phase. Acetonitrile and water in various volume ratios were used for the preparation of mobile phase. Because of higher elution strength, acetonitrile was chosen as an organic solvent.

To obtain the optimum conditions for the chromatographic determination of malathion, a series of experiments were performed by varying the volume ratio of acetonitrile and water in the mobile phase. The best chromatographic conditions were achieved using isocratic elution with a mobile phase consisted of acetonitrile-water $(50: 50, v / v)$ (Figure 2), a flow rate 


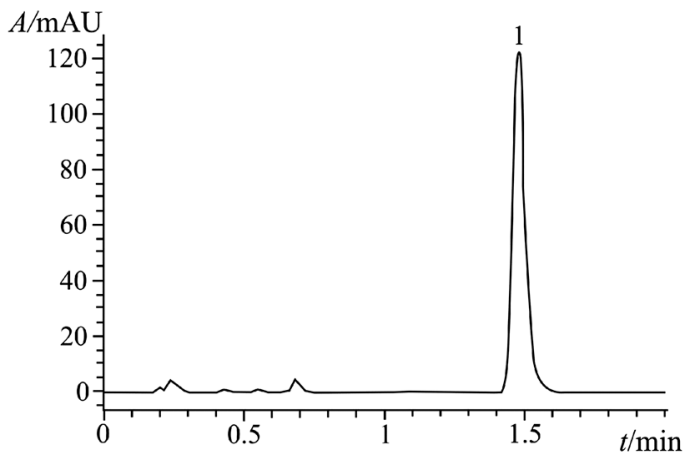

(a)

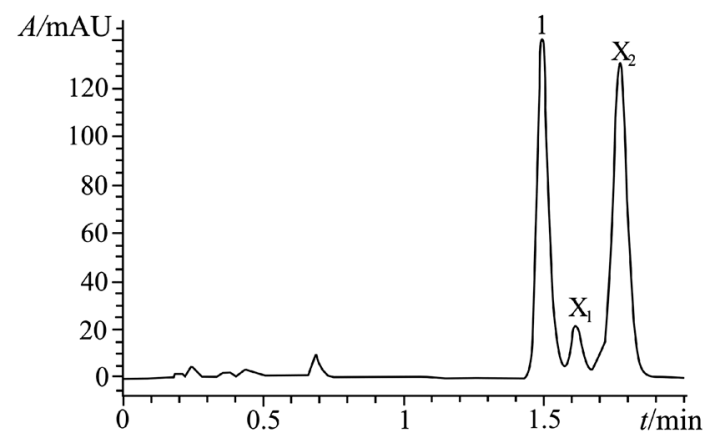

(b)

Figure 2. Chromatograms obtained from analytical standard of malathion (a) and pesticide formulation "Etiol tecni" (b) on the Poroshell EC $120-C 18$ column $(50 \mathrm{~mm} \times 3 \mathrm{~mm}, 2.7 \mu \mathrm{m})$ at $220 \mathrm{~nm}$ using the proposed method

of $1 \mathrm{~mL} / \mathrm{min}$, a constant column temperature at $25^{\circ} \mathrm{C}$, and $\mathrm{UV}$ detection at $220 \mathrm{~nm}$. Under these experimental conditions, a smooth baseline was obtained, and the chromatographic peak of malathion was high, narrow, and symmetrical, with a satisfactory value for the purity index (>999) (Figure 2a). The column dead time $\left(t_{0}\right)$ value was $0.19 \mathrm{~min}$, and the retention time $\left(t_{\mathrm{R}}\right)$ was $1.46 \mathrm{~min}$, so the calculated value for retention factor $\left(k^{\prime}\right)$ was 6.68. This value for the retention factor is less than 10 , which is the maximum acceptable value according to some authors for this parameter [20]. Under these stipulated conditions, a short retention time for malathion was obtained, which means a rapid chromatographic process for its quantification.

The chromatogram of the pesticide formulation obtained using the proposed method is shown in Figure 2b. As can be seen from Figure $2 b$, on the chromatogram of the pesticide formulation, in addition to the malathion peak (1), two more peaks of the unknown components were observed $\left(\mathrm{X}_{1}\right.$ and
$\mathrm{X}_{2}$ ) that eluted slower than malathion, with a retention time of $1.61 \mathrm{~min}$ and $1.77 \mathrm{~min}$. Their chromatographic peaks were almost completely separated to the baseline, and from the peak of interest, which was also confirmed by the calculated resolution values $\left(R_{\mathrm{S}}=2.56\right)$ and the separation factor $(\alpha=1.10)$ of the malathion peak and its neighboring peak $\left(\mathrm{X}_{1}\right)$.

Method Validation. Specificity, selectivity, linearity, precision expressed as intra-day and inter-day repeatability of retention time, peak area and peak height, and accuracy were examined to assess the validity of the developed method in accordance with the CIPAC and SANCO rules [21, 22].

Specificity and Selectivity. To confirm the specificity and selectivity of the developed method, UV-diode array detection was used to check the peak purity and analyte peak identity. The purity index of malathion was greater than 999 (the maximum value for the peak purity index (PPI) should be 1000), which means that the chromatographic peak was not affected by any other compound. In addition, identification of the analyte was done using the value for the retention time and match factor obtained by overlaid spectra of a pure analytical standard and absorption spectra of malathion in the pesticide formulation sample. Figure 3 shows the obtained overlaid spectra of pure analytical standard and absorption spectra of malathion in the pesticide formulation sample. The obtained value for match factors (999.915) confirmed the identity of the malathion.

Linearity. The linearity of the method was tested by constructing calibration curves that give the dependence of the peak area and the peak height on the injected amount of the analyte. For this purpose, a series of 5 working solutions of different concentration in the concentration range shown in Table 1 was prepared. As can be seen from this table, the values of the multiple correlation coefficients were $R^{2} \geq 0.9990$. Therefore, it can be concluded that the proposed method was characterized by excellent linearity in the investigated concentration range. The obtained results for multiple correlation coefficients $\left(R^{2}\right)$ indicated preferably the use of peak area as a variable.

Precision. Precision was expressed as repeatability of obtained results, which was evaluated for retention time, peak area, and peak height of the malathion from 8 successive injections of analytical standard with concentration $187.00 \mu \mathrm{g} / \mathrm{mL}$, within 3

Table 1. Statistical data for linearity

\begin{tabular}{lcc}
\hline Linearity range $(\mu \mathrm{g} / \mathrm{mL})$ & Regression equation & $R^{2}$ \\
\hline $46.75-374.00$ & $y^{a}=508.43 x+62.528$ & 0.9991 \\
& $y^{b}=122.66 x+33.697$ & 0.9990 \\
${ }^{a}$ Area. & & \\
${ }^{b}$ Height. & & \\
\hline
\end{tabular}

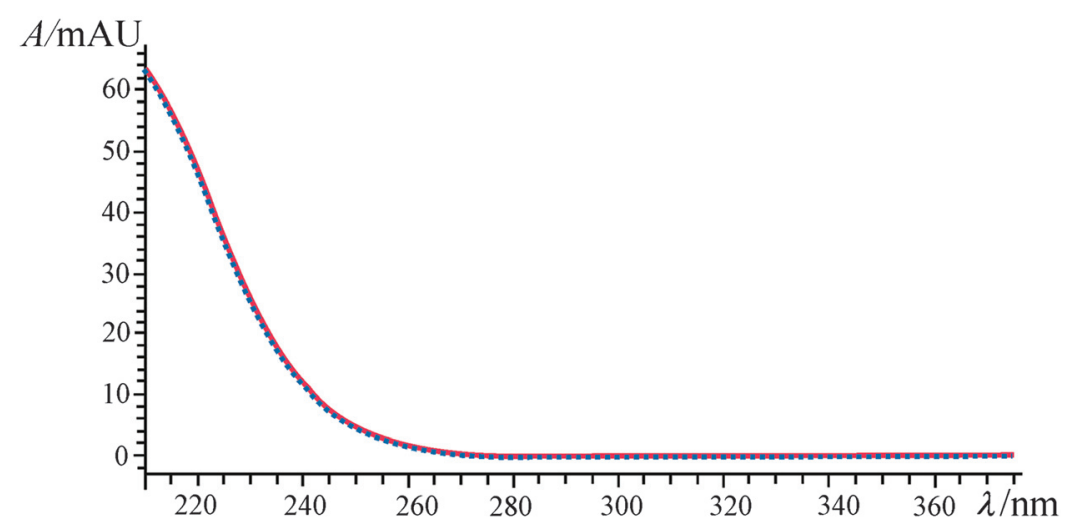

Figure 3. The overlaid UV spectra obtained by comparing the absorption spectra of a pure analytical standard of malathion and absorption spectra of the same analyte in the pesticide formulation 
Table 2. Statistical data for repeatability

\begin{tabular}{|c|c|c|c|c|c|c|c|c|}
\hline & \multicolumn{6}{|c|}{ Intra-day repeatability $(n=8)$} & \multicolumn{2}{|c|}{ Inter-day repeatability $(n=3)$} \\
\hline & \multicolumn{2}{|c|}{ I day } & \multicolumn{2}{|c|}{ II day } & \multicolumn{2}{|c|}{ III day } & \multirow[t]{2}{*}{$\bar{x} \pm \mathrm{SD}$} & \multirow[t]{2}{*}{ RSD (\%) } \\
\hline & $\bar{x} \pm \mathrm{SD}$ & RSD (\%) & $\bar{x} \pm \mathrm{SD}$ & $\overline{\mathrm{RSD}(\%)}$ & $\bar{x} \pm \mathrm{SD}$ & RSD (\%) & & \\
\hline Retention time (min) & $1.47 \pm 0.013$ & 0.88 & $1.46 \pm 0.020$ & 1.37 & $1.46 \pm 0.017$ & 1.17 & $1.46 \pm 0.017$ & 1.19 \\
\hline Peak area & $509.15 \pm 1.05$ & 0.20 & $501.01 \pm 3.87$ & 0.77 & $507.91 \pm 1.89$ & 0.37 & $506.02 \pm 4.40$ & 0.87 \\
\hline Peak height & $153.97 \pm 0.36$ & 0.23 & $155.06 \pm 1.34$ & 0.87 & $158.74 \pm 0.79$ & 0.49 & $155.92 \pm 2.25$ & 1.44 \\
\hline
\end{tabular}

Table 3. Results from recovery experiments $(n=4)$

\begin{tabular}{lcccc}
$\begin{array}{l}\text { Mass of } \\
\text { analyte }(\mu \mathrm{g})\end{array}$ & $\begin{array}{c}\text { Pure analyte } \\
\text { added }(\mu \mathrm{g})\end{array}$ & $\begin{array}{c}\text { Total analyte found } \\
(\mu \mathrm{g})( \pm \mathrm{SD})\end{array}$ & $\begin{array}{c}\text { Recovery } \\
(\%)\end{array}$ & $\begin{array}{c}\text { RSD } \\
(\%)\end{array}$ \\
\hline 0.46 & 0.12 & $0.57 \pm 0.0008$ & 98.24 & 0.15 \\
0.46 & 0.23 & $0.71 \pm 0.0004$ & 101.28 & 0.06 \\
0.46 & 0.47 & $0.95 \pm 0.0012$ & 102.00 & 0.13 \\
\hline
\end{tabular}

days (Table 2). The proposed method shows high precision in terms of retention time (RSD $=0.88-0.37 \%$ ), peak area $(\mathrm{RSD}=0.20-0.87 \%)$, and peak height $(\mathrm{RSD}=0,23-1.44 \%)$. The RSD values for the retention time, peak area, and peak height of malathion were calculated based on modified Horwitz equation, and the obtained results were within acceptable limits for RSD, which should not exceed 1.46\% [21,22].

Accuracy. The accuracy of the method was confirmed by standard additions $[21,22]$. The accuracy of the method was expressed as the deviation between the calculated mean value obtained by examination and the true value of the spiked amounts of the analyte into a sample matrix that already contains some quantity of the analyte (Table 3). The calculated values for the recovery (Table 3) were within the acceptable values according to the CIPAC and SANCO criteria $[21,22]$ and ranged from 98.24 to $102.00 \%$. According to these criteria, the values for the recovery should range from $98 \%$ to $102 \%$. Consequently, it was concluded that the proposed method is accurate enough for the determination of active ingredient malathion in the pesticide formulation "Etiol tecni".

The experimentally obtained value for the density of the pesticide formulation was $1.069 \mathrm{~g} / \mathrm{mL}$. The obtained mean concentration of active ingredient malathion in the pesticide formulation "Etiol tecni" was $597.13 \mathrm{~g} / \mathrm{L} \quad(n=4$, $\mathrm{RSD}=0.13 \%$ ), which corresponded to the value declared by the manufacturer.

\section{Conclusions}

The research within this study represents contribution in the field of developing of new analytical methods for determination of active substances in the plant protection products. To date, no analytical method for the determination of malathion in pesticide formulations by liquid chromatography (LC) has been published in the literature. A new, simple, and fast rapid resolution liquid chromatography method (RRLC) for determination of active ingredient malathion in the pesticide formulation "Etiol tecni", which is in the form of an emulsifiable concentrate (EC), has been developed and validated. Successful separation and quantification was achieved using a Poroshell EC $120-\mathrm{C} 18(50 \mathrm{~mm} \times 3 \mathrm{~mm}, 2.7 \mu \mathrm{m})$ analytical column and isocratic elution with a mobile phase consisted of acetonitrile-water $(50: 50, v / v)$, a flow rate of $1 \mathrm{~mL} / \mathrm{min}$, a constant column temperature at $25{ }^{\circ} \mathrm{C}$, and UV detection at $220 \mathrm{~nm}$. The results from the method validation revealed that the proposed method has a satisfactory linearity $\left(R^{2} \geq 0.9990\right)$ and excellent precision of retention time, peak area, and height. The obtained values for recoveries ranged from 98.24$102.00 \%$, with RSD of $0.06-0.15 \%$, revealed that the proposed method is convenient for routine determination of malathion in the emulsifiable concentrate pesticide formulation, according to the CIPAC and SANCO rules. The run time of analysis under the stipulated chromatographic conditions was about $2.5 \mathrm{~min}$. The short run time means that the proposed method requires a small volume $(<1.5 \mathrm{~mL})$ of the organic solvent (acetonitrile), which makes it cost-effective.

\section{References}

1. Regulation (EC) No $1107 / 2009$ of the European Parliament and of the Council of 21 October 2009, 2009.

2. EPA, Reregistration Eligibility Decision for malathion, 2009.

3. Tomlin, C. The Pesticide Manual Incorporating the Agrochemicals Handbook, $11^{\text {th }}$ Ed., Crop Protection Publications, 1997, pp. 630-631.

4. Miles, J. W.; Goette, M. B.; Guerrant, G. O.; Churchill, F. C. JAOAC, $1972,55,1133$

5. Orth, R. A.; Minett, W. Pestic. Sci., 1975, 6, 217. 496.

6. Hill, A. C.; Akhtar, M.; Mumtaz, M.; Osmani, J. A. Analyst, 1967, 92,

7. Prasada Rao, P. V. V.; Seshaiah, K.; Naidu, P. R. J. Agric. Food Chem., $1983,31,1370$

8. Sharma, S. R.; Rathore, H. S.; Ali, I.; Ahmed, S. R. Anal. Lett., 1985, 18,1181

9. Gouda, A. A.; Amin, A. S.; Sheikh, R. E.; Akl, M. A. Chem. Ind. Chem. Eng. Q., 2010, 16, 11 .

10. Reddy, K. M.; Suvardhan, K.; Kumar, K. S.; Rekha, D.; Chiranjeevi, P. E-J. Chem., 2005, 2, 187. (http://www.e-journals.net)

11. de Blas, O. J.; de Paz, J. L.; Mendez, J. H. Talanta, 1991, 38, 857.

12. Kumari, L. A.; Huat, T. G.; Kin, C. M. Malays. J. Sci., 2006, 25, 131, (URL: http://www.ejum.fsktm.um.edu.my).

13. Quintás, G.; Noé, A. M.; Armenta, S.; Garrigues, S.; de la Guardia, M. Anal. Chim. Acta, 2004, 502, 213.

14. Quintás, G.; Garrigues, S.; de la Guardia, M. Talanta, 2004, 63, 345.

15. CIPAC Method Handbook B (Malathion), 12/TC/M.2, 1983, pp. 1849 1859.

16. CIPAC Method Handbook K (Malathion), 12/TC/(M3)/2.1, 2003, pp. $89-94$.

17. Rugged fast LC performance oor HPLC/UHPLC, Agilent Technologies, Inc., 2012.

18. Agilent Poroshell 120 EC-C18 Threaded Column, Agilent Technologies, Inc., 2009

19. Agilent Poroshell 120 Columns for HPLC and UHPLC, Perform Rugged, Fast LC with confidence, Agilent Technologies, Inc., 2012.

20. Dong, M. W. Modern HPLC for Practicing Scientists, John Wiley \& Sons, Inc., Hoboken, New Jersey, 2006, pp. 17-46.

21. CIPAC Document 3807, Guidelines on method validation to be performed in support of analytical methods for agrochemical formulations, 2003. (http://www.cipac.org).

22. EUROPEAN COMMISSION, Directorate General Health and Consumer Protection, SANCO/3030/99 rev.5, Technical Active Substance and Plant protection products: Guidance for generating and reporting methods of analysis in support of pre-and post-registration data requirements for Annex (Section 4) of Regulation (EU) No 283/2013 and Annex (Section 5) of Regulation (EU) No 284/2013, 2019. 